\title{
The Impact of Azimuthally Asymmetric Carbon Deposition upon Pellet- Clad Mechanical Interaction in Advanced Gas Reactor Fuel
}

\author{
T.A. Haynes ${ }^{1}$, V. Podgurschi ${ }^{1} \&$ M.R. Wenman $^{1 *}$ \\ ${ }^{1}$ Centre for Nuclear Engineering \& Department of Materials, \\ Imperial College London, Exhibition Rd., London, SW7 2AZ \\ * Corresponding Author
}

\begin{abstract}
Cracked nuclear fuel pellets were modelled in the $r-\theta$ plane with an azimuthally varying clad surface temperature boundary condition using the PELICAN set of fuel performance models for the commercial finite element software, Abaqus. The temperature boundary condition was assumed to represent heat transfer impairment due to an azimuthally asymmetric carbon deposit on advanced gas-cooled reactor pins. The model predicts the radial and azimuthal displacement of the idealised fuel fragments, together with the resulting elastic, creep and plastic strains in the cladding. These were compared to simulations assuming a uniformly hot or cold boundary condition. Apart from a short period during the return to power from reduced power $(70 \%)$ operation and outages, the hoop stress in the simulation with an azimuthally varying clad surface temperature was bounded by that of models with a uniform hot or cold surface temperature. The reduced stress was proposed to be due to the greater ability of the fuel fragments to relocate in order to accommodate changes to the power level. As a result, the creep strains in the model with an azimuthally varying clad surface temperature were lower than assuming either a uniform hot or cold boundary condition.
\end{abstract}

\section{Highlights}

- Azimuthally asymmetric carbon deposition on AGR fuel pins is modelled.

- Carbon deposition is shown to significantly increase the cladding creep rate.

- Asymmetric deposition does not further increase the cladding creep strain.

\section{Key Words}

PCMI, Nuclear Fuel, deposit, AGR 


\section{Introduction}

\section{Pellet-Clad Mechanical Interaction}

Pellet-cladding interaction (PCI) is a phenomenon in nuclear fuel rods whereby the outer surface of a cracked fuel pellet comes into contact with the inner surface of the cladding. It can occur during power transients, in incidental transients, fuel manoeuvring and during steady state operation. In an advanced gas-cooled reactor (AGR), the initial radial gap between the pellets and the cladding is smaller than in light water reactors at 20-50 $\mu \mathrm{m}$. This, and the increased creep rate compared to a light water reactor (LWR), causes contact to occur at burnups of as little as $5 \mathrm{GWd} / \mathrm{tU}$ [1] (approximately a sixth of fuel life). In AGRs, clad damage occurs mainly by means of creep damage [2] rather than iodine-assisted stress corrosion cracking, as is the case in [3]-[5]. Pellet-clad mechanical interaction (PCMI) is a subset of PCI conditions, under which the role of fission products is not considered specifically.

Modelling PCMI is difficult as various coupled simultaneous mechanisms that occur at a wide range of length and timescales must be taken into account. As well as the pellet cracks, the pellet-cladding interface and the friction coefficients employed must also be considered. In particular, a strong bond can develop between the cladding and fuel pellet in the AGR. Following power manoeuvres, this can lead to the formation of a thin sliver of fuel (approximately $150 \mu \mathrm{m}$ in thickness) bonded to the cladding [2][6].

\section{Changes to Fuel Microstructure}

One technique used to identify the operating conditions in-pile is phase changes in the cladding. For AGR cladding aged under irradiation conditions, several phases can be precipitated: $\mathrm{Nb}(\mathrm{CN})$, G-phase $\left(\mathrm{Ni}_{16} \mathrm{Nb}_{6} \mathrm{Si}_{7}\right)$ and sigma $(\sigma)$ phase [7]. The $\sigma$ phase is a hard and brittle intermetallic compound, composed mainly of $\mathrm{Cr}$ and $\mathrm{Fe}$ and formed through the decomposition of delta ferrite [8], [9]. Sigma phase precipitates most rapidly at temperatures between 800 and $850^{\circ} \mathrm{C}$ [9], [10]. Only limited precipitation is observed under normal conditions and its presence can therefore be used to ascertain historic cladding temperatures [10].

\section{Carbon Deposition}

The graphite moderator of an AGR reactor is a structural component and cannot be replaced. During operation, the graphite undergoes radiation induced corrosion by carbon dioxide [11]; this can be described by the Boudouard reaction:

$$
\mathrm{CO}_{2}+\mathrm{C} \leftrightharpoons 2 \mathrm{CO}
$$


In the earlier MAGNOX reactors, carbon monoxide was injected to the core to prevent corrosion. In the AGR, methane is added to inhibit the reaction and therefore prevent excessive deposition of carbon on the core internals. The methane reacts with carbon dioxide complexes formed by radiation in preference to the graphite moderator. Nevertheless, carbon can still be deposited due to both the radiolytic decomposition of methane into hydrogen, ethane dissociation [12]; and, the reverse Boudouard reaction [13].

Whilst the ribs on an AGR fuel pin promote heat transfer by promoting the turbulent flow of the coolant and mixing, the deposition of carbon onto the cladding has a detrimental impact upon heat transfer out of the cladding [14], [15]. The Office for Nuclear Regulation's Nuclear Safety Technical Assessment Guide notes that "a $0.1 \mathrm{~mm}$ thick carbon layer on the fuel elements can reduce heat transfer so drastically that the elements undergo damage" [16]. It should be noted that deposits of up to $300 \mu \mathrm{m}$ have been reported [17]. Whilst early researchers examined the heat transfer impairment in fuel pins due to carbon deposition through empirical methods, Keshmiri has considered the thermal-mechanical performance of an entire fuel element [18]. The heat transfer impairment associated with carbon deposition is due not only to the deposit depth, but the low density of certain deposits [19]. These deposits of carbon have a very low density and hence high level of porosity; it is this porosity which significantly impairs the thermal conductivity of the deposit. Carbon deposits have been observed to possess a wide range of morphologies; examples of a number of morphologies are given in [20]. One morphology which offers particularly high impairment is when a thin dense deposit lies above a low density columnar deposit.

The deposition of carbon onto the cladding is catalysed by transition metals [16], in particular nickel [21]. Nickel can either be found in the steel as an alloying element (intrinsic nickel) or be transported from other core internals (extrinsic nickel) [22]. A number of approaches have been taken to mitigate carbon deposition. These include the injection of carbonyl sulphide [12] and increasing the thickness of the protective oxide layer on fresh cladding [20].

In a number of cases, the thickness and/or morphology of carbon deposits has varied azimuthally around the fuel pin. In the context of a cylindrical coordinate system such as is natural for a vertically mounted fuel pin, the azimuthal direction is defined as being in the horizontal plane and orbiting the vertical axis; it is perpendicular to the pin radius. Based upon the observation of sigma phase formation in post-irradiation examination (PIE), this has been inferred to give rise to a cross-pin temperature difference of up to $250 \mathrm{~K}$ [23]. Consequently, there is a possibility of increased asymmetric pellet fragment movement. 


\section{Modelling AGR Fuel Performance}

The 1.5-dimension fuel performance code ENIGMA is unable to model azimuthally changing temperature variation. It is therefore assumed that the behaviour of the fuel is bounded by that on the hot and cold sides and that all phenomena of interest are bounded by these two limiting cases.

This paper investigates the hypothesis that it is the higher temperature that impacts PCMI and not the temperature difference. The effect of the temperature profile was modelled using the PELICAN $(r-\theta)$ coupled temperature-displacement finite element model recently developed at Imperial College London for the AGR system [6], [24][25]. PELICAN is a development of Mella and Wenman's ( $r-z)$ axisymmetric model [26] and is able to model the $r-\theta$ plane of nuclear fuel. It has recently been extended to model the axial and radial motion of fuel fragments in order to simulate clad ballooning in LWRs [27].

\section{Methodology}

The PELICAN Approach

The PELICAN fuel performance models have been thoroughly described elsewhere [25], [28]. In summary, they consist of a series of coupled temperature-displacement finite element models built within the commercial software Abaqus, combined with a number of user-defined subroutines written in FORTRAN and parameter files detailing specific fuel properties and simulation parameters.

Material properties are determined as empirical functions of temperature, burn-up and stress state. In cladding materials, PELICAN can consider the evolution of irradiation creep, thermal creep, thermal expansion, time-independent plasticity, irradiation growth and thermal conductivity. In fuel materials, it is able to predict thermal expansion, densification, thermal conductivity, gaseous fission product swelling, solid fission product swelling, thermal diffusion creep, thermal dislocation creep and irradiation creep. The radial power deposition using the RADAR model [29]. The code has been validated for centreline temperature and diametric strain against a range of instrumented fuel assembly data sets from Halden [28]. 


\section{The Finite Element Model Used}

A model of the whole $r-\theta$ plane with cracked fuel pellets was created; this is shown in Figure 1. In order to increase the stability of the model and decrease the computational time, the symmetry of the system was exploited by setting at each point in a pair shown in Figure 1, the radial displacement to be equal and the azimuthal displacement to be opposite.

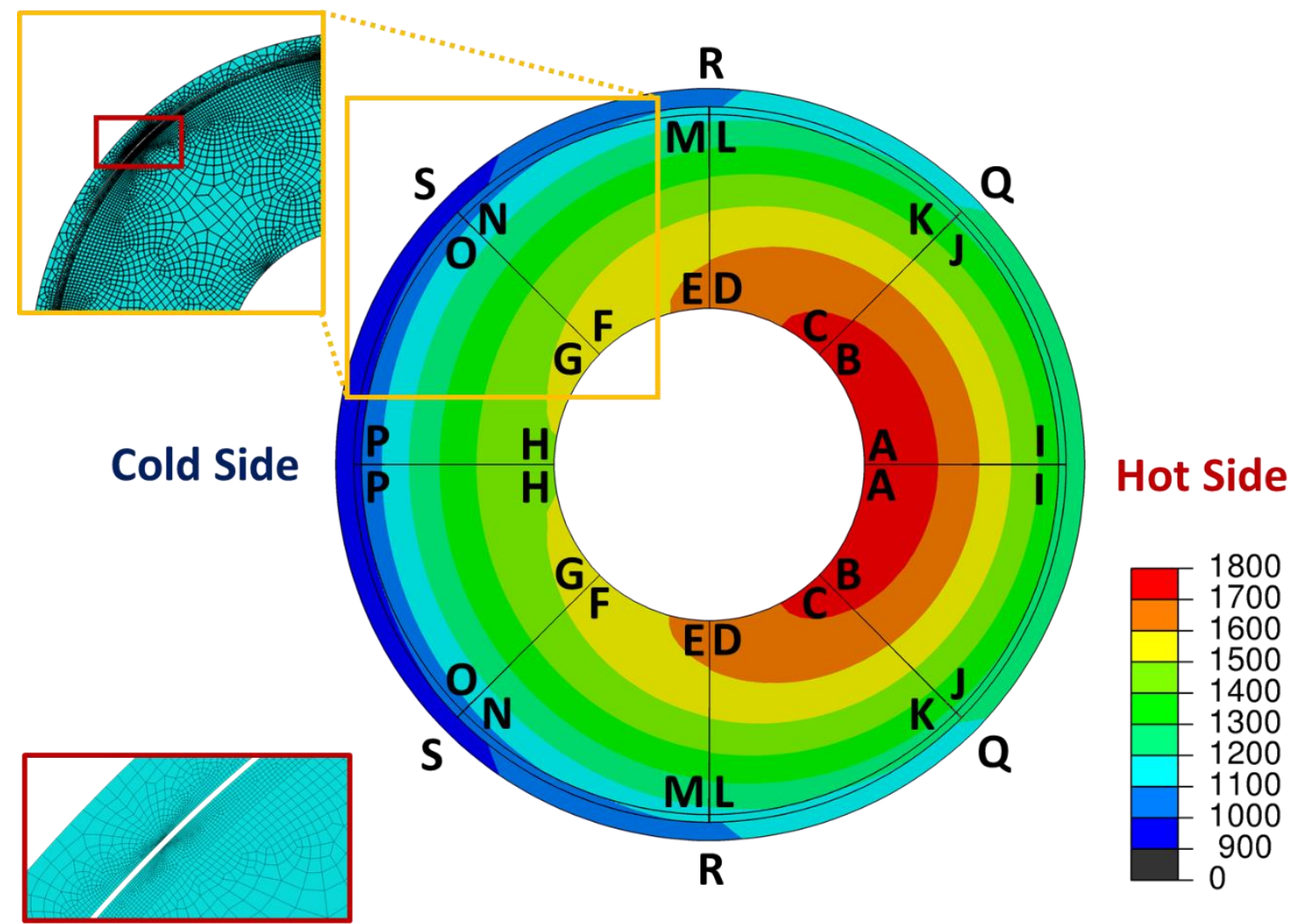

Figure 1 - The symmetry points on the pellet fragments $(A-I)$ and the cladding $(Q-S)$. Contours show the temperature in Kelvin whilst at the end of a typical simulation. Inserts show the finite element mesh employed.

The model contained 15,887 CPEG4T (four-node, generalized plane strain, thermally coupled linear displacement and temperature) elements; these are represented in the contour plot shown in Figure 1. The mesh selected was subjected to a mesh sensitivity study; this gave an error of $0.5 \mathrm{~K}$ in the peak fuel temperature; $4 \mathrm{MPa}$ in the peak cladding stress and $10 \%$ in the peak clad creep strain. The simulations were carried out on a single core of a $3.50 \mathrm{GHz}$ Intel Xeon E52637 processor running on a computer with 64 GB of RAM. Parallelisation was not used due to the relatively poor parallelisation capability of Abaqus 6.13 and the use of common blocks not designed for parallelism. The model with an azimuthally varying boundary condition took 44.5 hours to run.

Heat transfer across the radial pellet cracks is based upon the URGAP model [30], [31]. It is described in more detail in [25]. As per our previous work [25], a coefficient of friction of 0.8 
was applied between all surfaces. In this paper, we report the results obtained for fuel element four with no clad-fuel bonding. This was justified based upon similar trends in creep strain and hoop stress in bonded and un-bonded fuel having being been previously predicted along a fuel channel [28]. No account was made for a sliver of fuel bonded to the cladding.

The model makes the assumption that the pellet waist may be approximated by generalised plane strain. Clearly this is not applicable to either pellet ends or anti-stacking groves, where a triaxial stress state might be expected. One argument which could be put forward for the applicability of this approach to the AGR is that clad bore cracks have been observed to extend along the length of a number of fuel pellets [23], [32]. This should be contrasted with PCI failures in LWRs and CANDU reactors, which are frequently described as pin-point cracks associated with the triple point where pellet radial cracks meet the cladding at pellet ends [33]. The peak temperature was aligned with a radial crack in order to exploit symmetry and set various displacements to be equal. This results in the maximum temperature gradient in the cladding being aligned with a radial crack (at position ' $R$ ' in Figure 1). An alternative would have been to align the peak temperature with the centre of a fuel fragment. It should be noted that of the eight radial cracks in the model, six will be in positions where there is a temperature gradient across the crack tip.

\section{Operating Conditions}

AGR cores consist of around three hundred vertical fuel channels, each containing a single fuel stringer [34]. Each stringer consists of typically eight $1 \mathrm{~m}$ long fuel elements (containing 36 fuel pins) stacked on top of each other and numbered from 1 at the bottom to 8 at the top. Figure 2 shows the cladding surface temperatures assumed for each fuel element; these values are representative of the wide range of operating conditions seen across the core. 


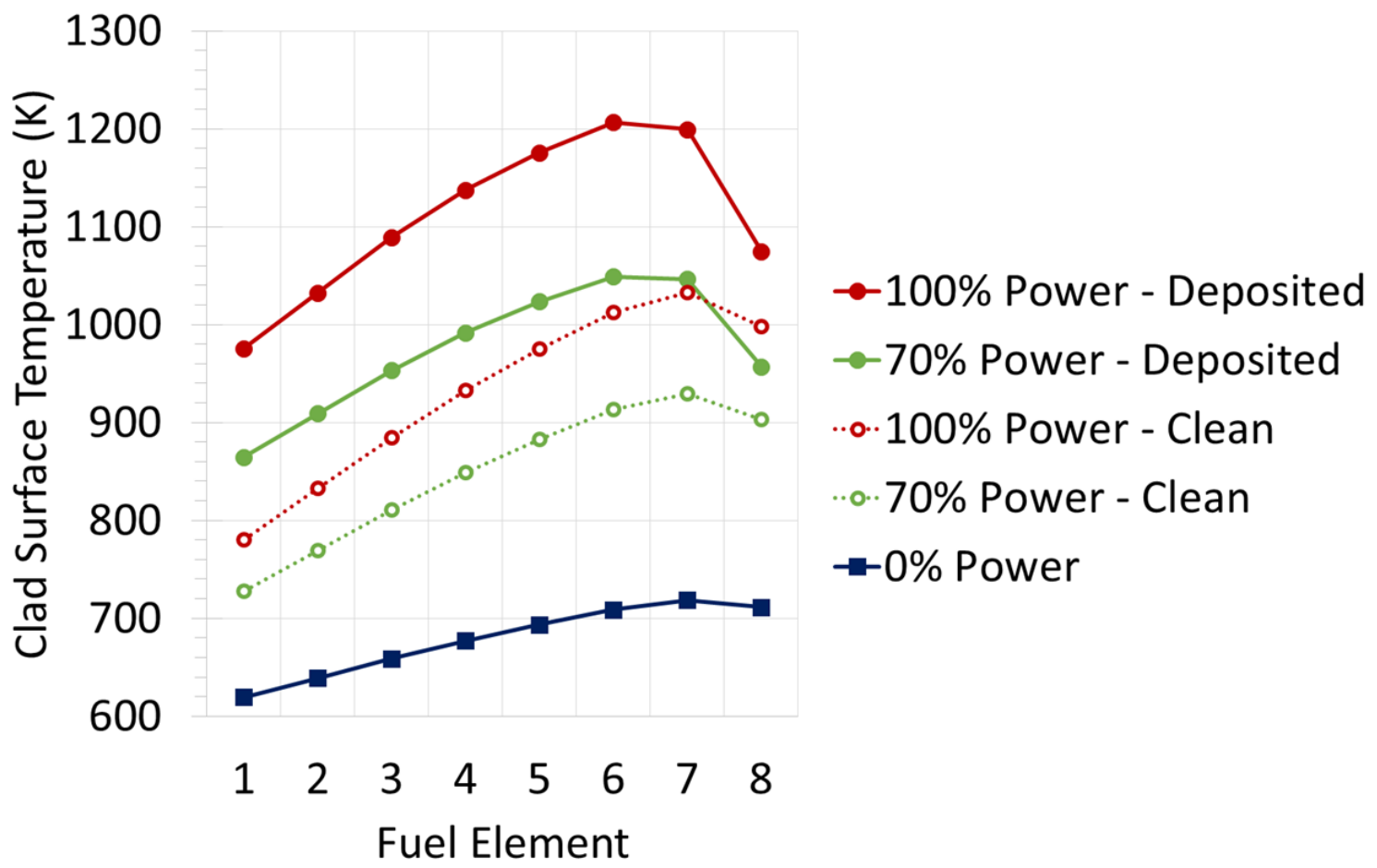

Figure 2 - The cladding surface temperature along an AGR fuel channel used for the deposited, un-deposited and cross-pin temperature tilt simulations. Fuel elements are numbered from the bottom to the top of the fuel channel.

In order to account for a cross-pin temperature tilt of approximately $200 \mathrm{~K}$, the deposited cladding surface temperature was increased in proportion to the linear power rating. The tilt was defined as the maximum difference between temperatures on the outside surface of the cladding on opposite sides of the fuel pin. The cross-pin temperature tilt of $200 \mathrm{~K}$ was assumed to represent examples of azimuthally varying carbon deposition in heavily deposited fuel rather than a worst case value. The tilt value used reflects cladding temperatures inferred from microstructural observations in PIE rather than a specific deposit conductivity. The additional increased temperature was imposed throughout the simulation since the deposit was assumed to be present during the entire life. This is a conservative assumption based upon the varying deposit thickness, morphology and incubation time across the AGR fleet.

The cladding temperature boundary condition was introduced, according to equation (1), in which $T$ was the temperature applied (in $\mathrm{K}$ ); $T_{0}$ the un-deposited cladding temperature; $R$, the linear rating (in $\left.\mathrm{kW} \mathrm{m}^{-1}\right) ; \vartheta$, the additional temperature per unit linear rating $\left(10 \mathrm{~K} \mathrm{~kW}^{-1} \mathrm{~m}\right)$ and $\phi$, the azimuthal angle.

$$
T=T_{0}+\vartheta R \cos \varnothing
$$

The smoothly varying functional form in equation (1) was introduced to represent a pin with thicker deposit on one side than the other. Given that AGR fuel elements consist of a number 
of pins surrounded by a graphite sleeve, this could be argued to represent an outer and inner facing side. The sensitivity of the model to the functional form was not investigated.

Simulations Run

Simulations were run with cladding outer surface temperature boundary conditions representing:

- azimuthally-uniform carbon deposit;

- un-deposited cladding; and,

- azimuthally-varying deposited cladding.

Table 1 shows the steps used in the simulation. This idealised history was based upon the recommendation of Ball [35]. It represents the following phases of operation:

- six months of full-power operation;

- a six week outage;

- full power operation for three months;

- a period of reduced power operation of one month, representing a period during which only three of the four cooling circuits were operational;

- full power operation; and,

- a severe fault, leading to a power-ramp to $150 \%$ power over $100 \mathrm{~s}$. 
Table 1- The steps used to model fuel operation.

\begin{tabular}{|c|c|c|c|c|c|c|c|c|c|}
\hline \multirow[t]{2}{*}{ Description } & \multirow[t]{2}{*}{$\begin{array}{l}\text { Duration } \\
\text { (days) }\end{array}$} & \multicolumn{2}{|c|}{ Increment $(s)$} & \multicolumn{2}{|c|}{$\begin{array}{c}\text { Un-deposited Clad } \\
\text { Surface Temperature } \\
(K)\end{array}$} & \multicolumn{2}{|c|}{$\begin{array}{c}\text { Deposited Clad } \\
\text { Surface Temperature } \\
(K)\end{array}$} & \multicolumn{2}{|c|}{$\begin{array}{c}\text { Linear Rating Power } \\
\text { Rating }\left(k^{-1} m^{-1}\right)\end{array}$} \\
\hline & & Initial & Maximum & Initial & Final & Initial & Final & Initial & Final \\
\hline $\begin{array}{l}\text { Initial Power } \\
\text { Increase }\end{array}$ & 3.000 & $3,600.0$ & $25,920.0$ & 293.15 & 932.45 & 293.15 & $1,132.95$ & $\begin{array}{l}0.00 \\
(0 \%)\end{array}$ & $\begin{array}{c}20.50 \\
(100 \%)\end{array}$ \\
\hline $\begin{array}{c}\text { Full Power } \\
\text { Operation }\end{array}$ & 180.000 & $3,600.0$ & $20,000.0$ & 932.45 & 932.45 & $1,132.95$ & $1,132.95$ & $\begin{array}{c}20.5 \\
(100 \%)\end{array}$ & $\begin{array}{c}20.50 \\
(100 \%)\end{array}$ \\
\hline Shutdown & 1.000 & $3,600.0$ & $8,640.0$ & 932.45 & 678.02 & $1,132.95$ & 678.02 & $\begin{array}{c}20.5 \\
(100 \%)\end{array}$ & $\begin{array}{c}0.14 \\
(0.68 \%)\end{array}$ \\
\hline Outage & 42.000 & $3,600.0$ & $86,400.0$ & 678.02 & 678.02 & 678.02 & 678.02 & $\begin{array}{c}0.14 \\
(0.68 \%)\end{array}$ & $\begin{array}{c}0.07 \\
(0.32 \%)\end{array}$ \\
\hline Restart & 3.000 & $3,600.0$ & $25,920.0$ & 678.02 & 932.45 & 678.02 & $1,132.95$ & $\begin{array}{c}0.07 \\
(0.32 \%)\end{array}$ & $\begin{array}{c}20.50 \\
(100 \%)\end{array}$ \\
\hline $\begin{array}{l}\text { Full Power } \\
\text { Operation }\end{array}$ & 75.000 & $3,600.0$ & $86,400.0$ & 932.45 & 932.45 & $1,132.95$ & $1,132.95$ & $\begin{array}{c}20.50 \\
(100 \%)\end{array}$ & $\begin{array}{c}20.50 \\
(100 \%)\end{array}$ \\
\hline $\begin{array}{c}\text { Power } \\
\text { Reduction }\end{array}$ & $\begin{array}{l}0.400 \\
(10 \mathrm{~h})\end{array}$ & 360.0 & $3,600.0$ & 932.45 & 848.85 & $1,132.95$ & 988.35 & $\begin{array}{c}20.50 \\
(100 \%)\end{array}$ & $\begin{array}{l}14.30 \\
(70 \%)\end{array}$ \\
\hline $\begin{array}{l}\text { Reduced } \\
\text { Power }\end{array}$ & 30.000 & $3,600.0$ & $86,400.0$ & 848.85 & 848.85 & 988.35 & 988.35 & $\begin{array}{l}14.30 \\
(70 \%)\end{array}$ & $\begin{array}{l}14.30 \\
(70 \%)\end{array}$ \\
\hline $\begin{array}{l}\text { Power } \\
\text { Increase }\end{array}$ & $\begin{array}{l}0.400 \\
(10 \mathrm{~h})\end{array}$ & 360.0 & $3,600.0$ & 848.85 & 932.45 & 988.35 & $1,132.95$ & $\begin{array}{l}14.30 \\
(70 \%)\end{array}$ & $\begin{array}{c}20.50 \\
(100 \%)\end{array}$ \\
\hline $\begin{array}{l}\text { Full Power } \\
\text { Operation }\end{array}$ & 75.000 & $3,600.0$ & $86,400.0$ & 932.45 & 932.45 & $1,132.95$ & $1,132.95$ & $\begin{array}{c}20.50 \\
(100 \%)\end{array}$ & $\begin{array}{c}20.50 \\
(100 \%)\end{array}$ \\
\hline Ramp & $\begin{array}{l}0.001 \\
(100 \mathrm{~s})\end{array}$ & 0.1 & 0.1 & 932.45 & 932.45 & $1,132.95$ & $1,132.95$ & $\begin{array}{c}20.50 \\
(100 \%)\end{array}$ & $\begin{array}{c}30.75 \\
(150 \%)\end{array}$ \\
\hline
\end{tabular}




\section{Results \& Discussion}

\section{Fuel Temperature}

Figure 3 shows the temperature at the end of the final ramp step to $150 \%$ power, together with the points $\alpha, \beta, \gamma, \delta$ and $\varepsilon$ referred to in later figures. It is clear that the cross pin temperature tilt extends into the centre of the pellet. The temperature on the hot side of the cladding is 1240 $\mathrm{K}$ and on the cold side, $933 \mathrm{~K}$, giving a cross-pin temperature tilt on the cladding of $307 \mathrm{~K}$ [at $30.75 \mathrm{~kW} \mathrm{~m}^{-1}$ ]. On the hot side of the central pellet bore, the temperature is $1776 \mathrm{~K}$ and on the cold side it is $1498 \mathrm{~K}$, a difference of $278 \mathrm{~K}$. The tilt at the pellet bore is therefore $90 \%$ of that on the cladding outer surface; prior to the ramp in power to $150 \%$, the equivalent value was $87 \%$.
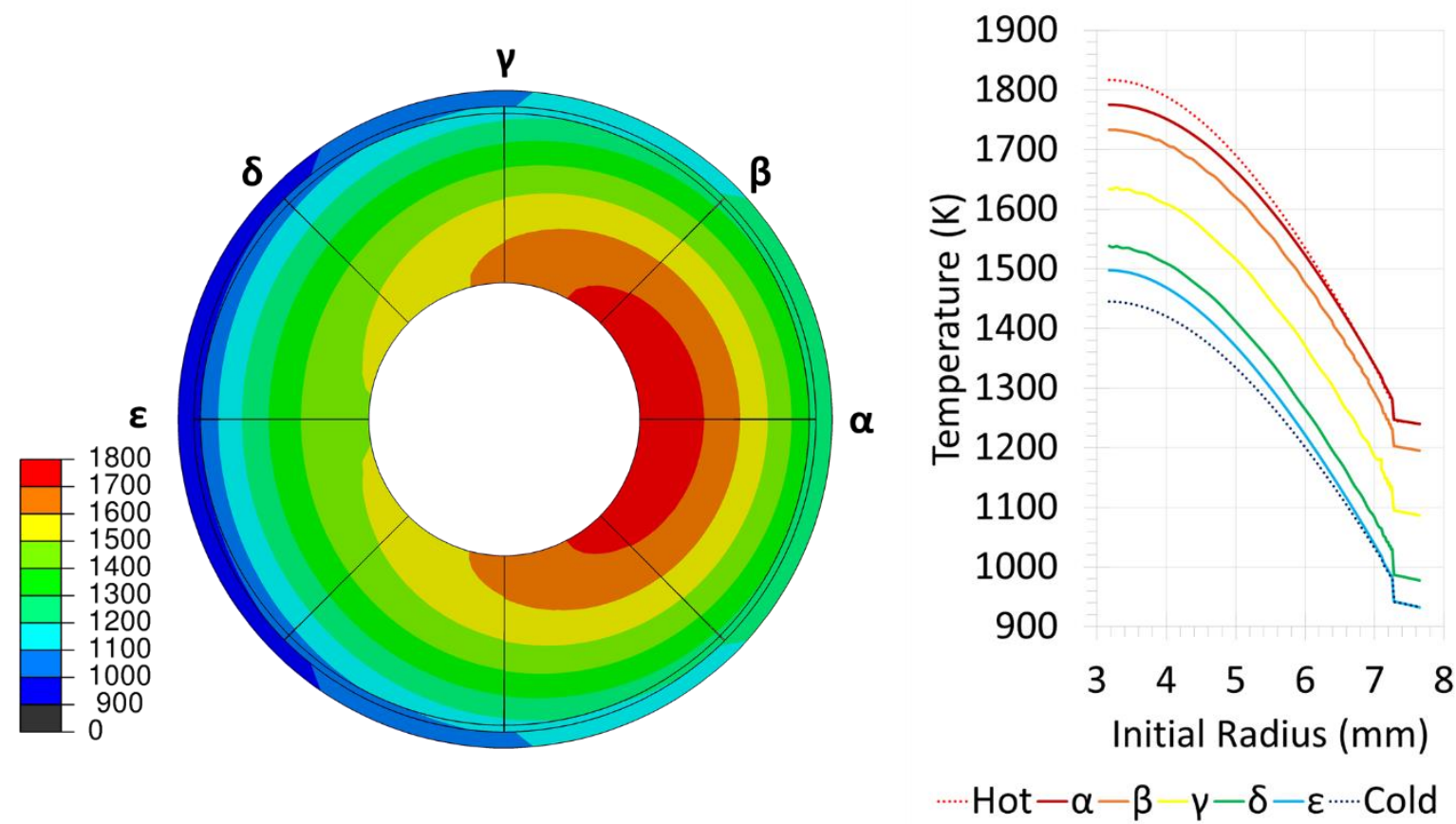

Figure 3 - The temperature (in Kelvin) of the fuel at the end of the ramp to $150 \%$. The points $\alpha, \beta, \gamma, \delta$ and $\varepsilon$ are referred to in later figures. The radial temperature profiles through the fuel at these positions and for uniform temperature boundary conditions are given on the right hand of the image.

For the simulations of cladding with a uniform temperature, the temperature at the bore at the end of the ramp was $1447 \mathrm{~K}$ for a model with completely clean pin, and $1818 \mathrm{~K}$ in the deposited model. Modelling a cross-pin temperature tilt rather than the hot and cold sides separately reduced the peak temperature in the fuel by $42 \mathrm{~K}$. This is likely to be due to the sinusoidal temperature boundary condition meaning that less of the fuel is exposed to the highest temperature. Whilst PELICAN does not currently have the ability to model fission gas release, the level of temperature change predicted by this model is likely to have a significant impact upon the fission gas release. Modelling a pin with an azimuthal carbon deposit, and hence with 
temperature tilt, by simply using a 'hot pin' therefore represents an over-estimate of the maximum temperature reached in the fuel and is a thermally somewhat conservative.

\section{Azimuthal Motion of Pellet Fragments}

Figure 4 shows the bulk azimuthal motion of the pellet fragments at the points $\beta, \gamma$ and $\delta$ shown in Figure 3. The pellet fragments are displaced towards the cold side of the fuel by several microns when at power. During the outage, the displacement reverses, with bulk displacement towards the hot side. This is due to creep in the ceramic fuel pellet fragments whilst at full power for long periods. During the period of reduced power operation, the displacement is reduced and during the ramp to $150 \%$ power it increases to between 5 and $8 \mu \mathrm{m}$.

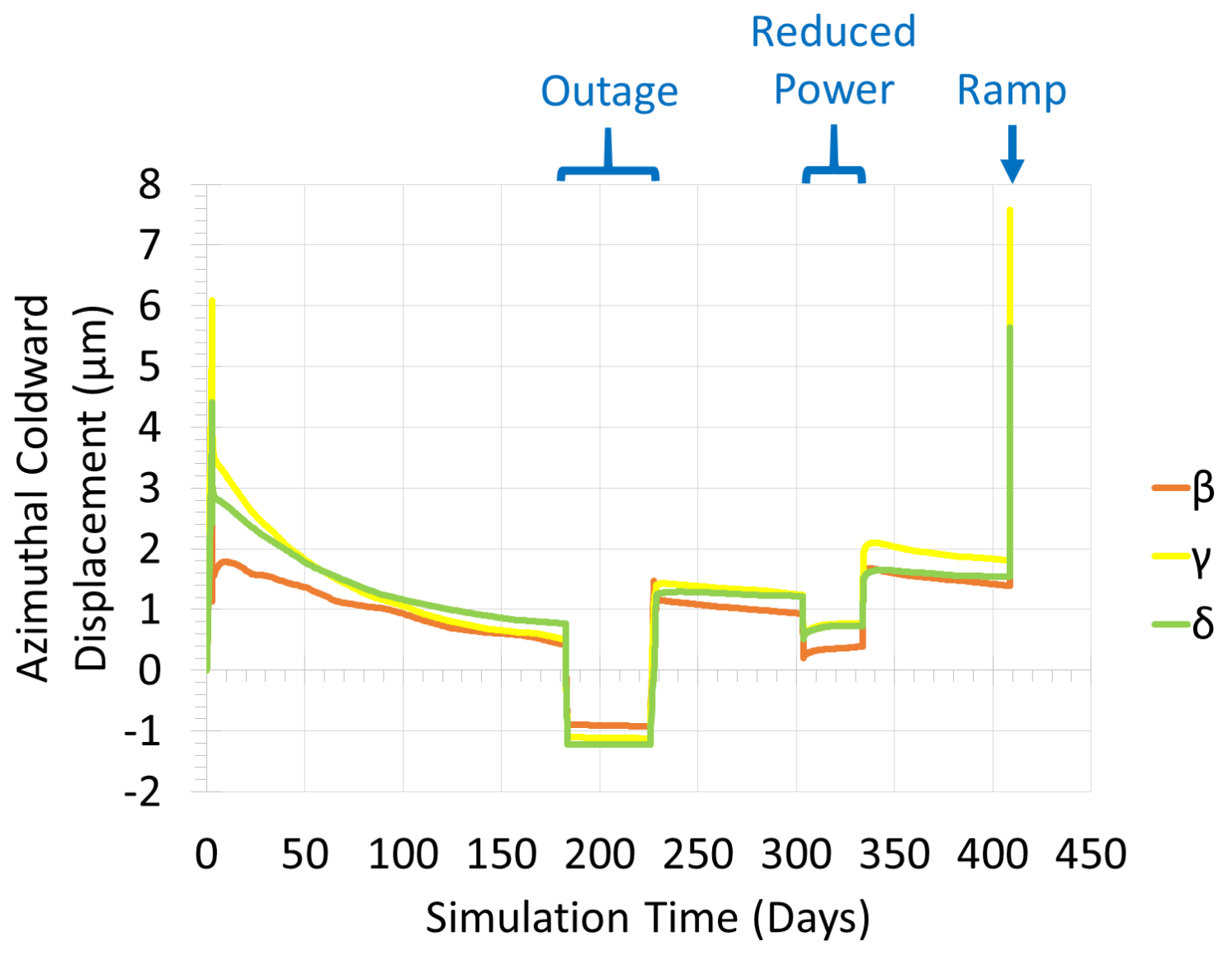

Figure 4 - The azimuthal bulk motion of the pellet fragments towards the cool side of the pin at the points $\beta, \gamma$ and $\delta$ in Figure 3.

This immediately demonstrates the benefit of modelling the entire $r-\theta$ plane as it captures the coupled interaction of the hot side of the pin with the cold side. This effectively allows the hot side to be less constrained than it would be in a model with a uniform deposited boundary condition. 
Figure 5 shows the opening and closing of the pellet cracks opening at pellet inner and outer surfaces at each of the key points in Figure 3 and in the models with uniform deposited and undeposited boundary conditions. Figure 5(a) shows that whilst at full power (e.g. 90-150 days), the cracks at the pellet outer surfaces are more open at positions $\alpha$ and $\varepsilon$ than in the models with a uniform temperature boundary condition. At the end of the ramp, the crack width was $10.9 \mu \mathrm{m}$ at position $\gamma$, this is greater than the $8.3 \mu \mathrm{m}$ in the uniform un-deposited 'cold' model and $6.5 \mu \mathrm{m}$ in the uniformly deposited 'hot' model. The crack width at the bore, shown in Figure 5(b), is bounded by that of the uniform hot clad model and is generally lower for the model with a varying rather than uniform boundary condition. For example, the peak opening during the outage (160 days) was lower at point $\varepsilon$ than in the uniform cold model. Taken together, Figure 5(a) and (b) show that the crack tip motion is greater and more variable in the model with a cross pin temperature tilt than in a model with a uniform cladding temperature and that the crack opening at the pellet bore is less.
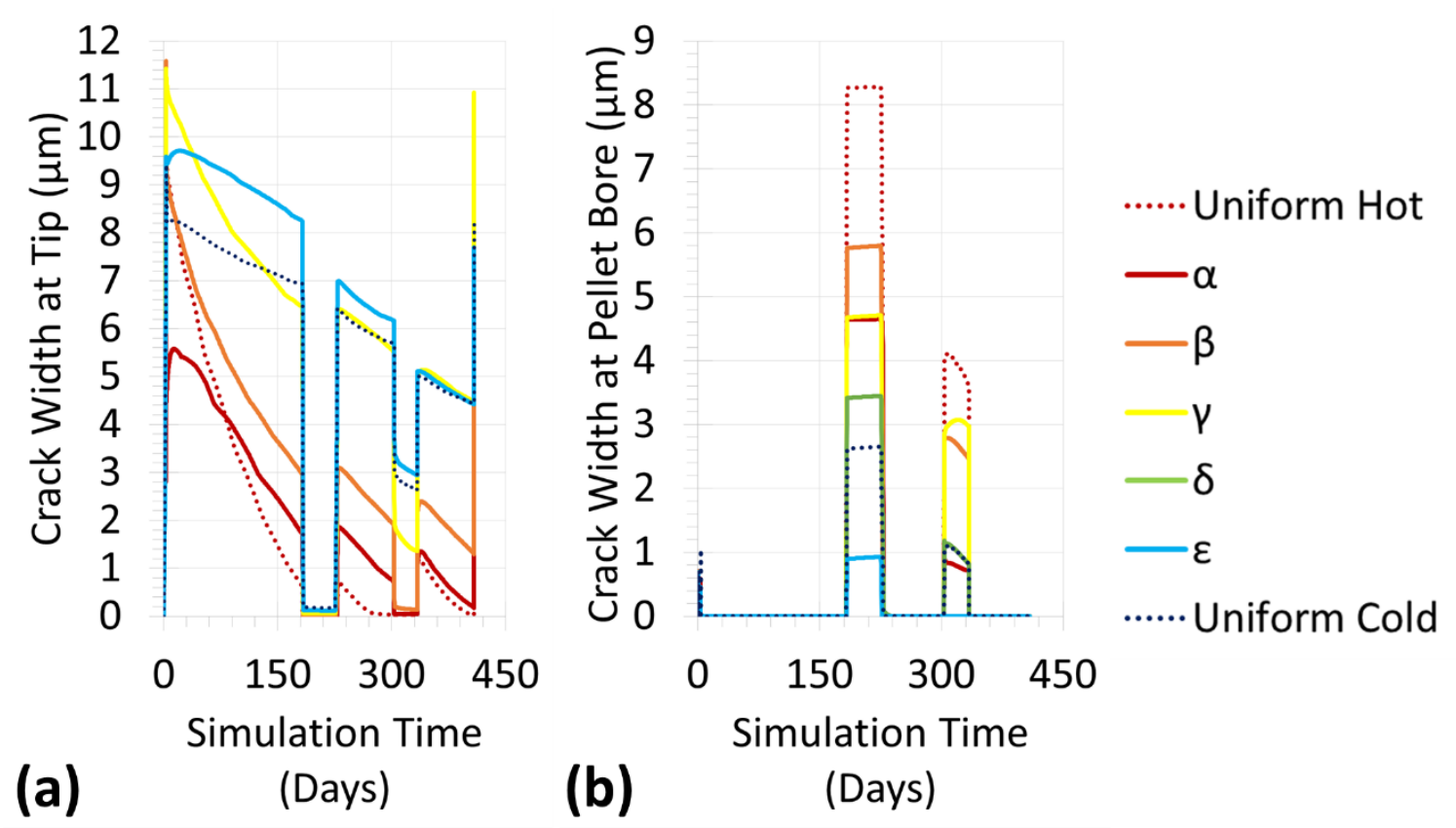

Figure 5 - The opening and closing of the pellet cracks at (a), the cladding inner surface and (b), the pellet bore at each of the key points in Figure 3, together with the equivalent positions in models with uniform temperature boundary conditions.

Whilst displacements of a magnitude of 5- $10 \mu \mathrm{m}$ might at first sight appear trivial, previous work [6] has shown the importance upon the stress state of pellet fragment displacement of this order. The key difference between a manufacturing tolerance and these displacements is that they are applied during PCMI and after the fuel has been 'conditioned'. The sensitivity of the displacements predicted by PELICAN to the constituent sub-models employed has been described elsewhere [28]. 


\section{Hoop Stress in the Cladding}

Figure 6 shows the hoop stress in the cladding at each of the key points in Figure 3, together with that at equivalent points in models with uniform temperature boundary conditions. It is complemented by Figure 7, which shows the maximum and minimum hoop stress at each point together with that at the end of the $150 \%$ power ramp and Figure 8 , which shows the stresses during the up-rates from the outage and period of reduced power operation.

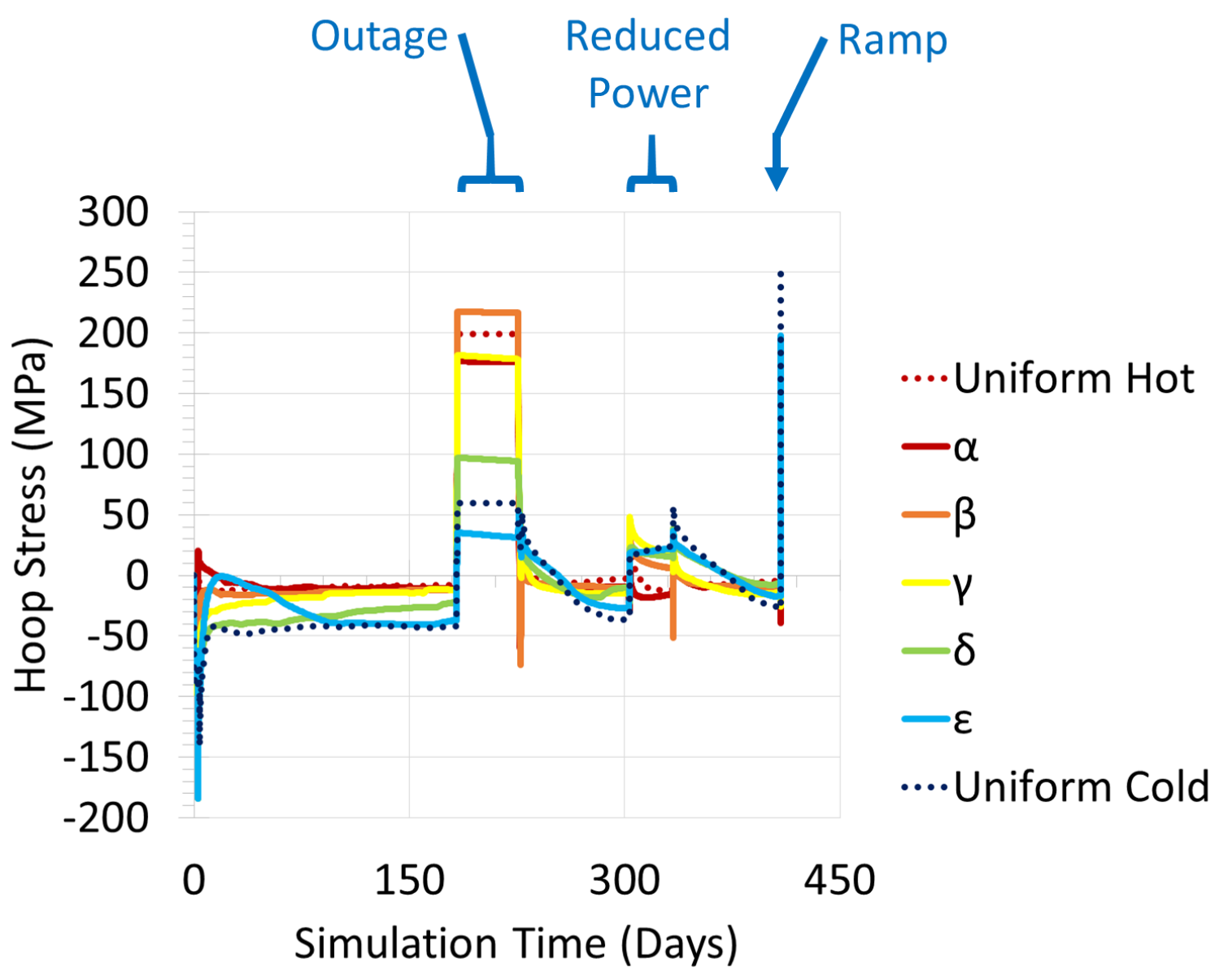

Figure 6 - The cladding hoop stress during the entire simulation at each of the key points in Figure 3, together with the equivalent positions in models with uniform temperature boundary conditions. 


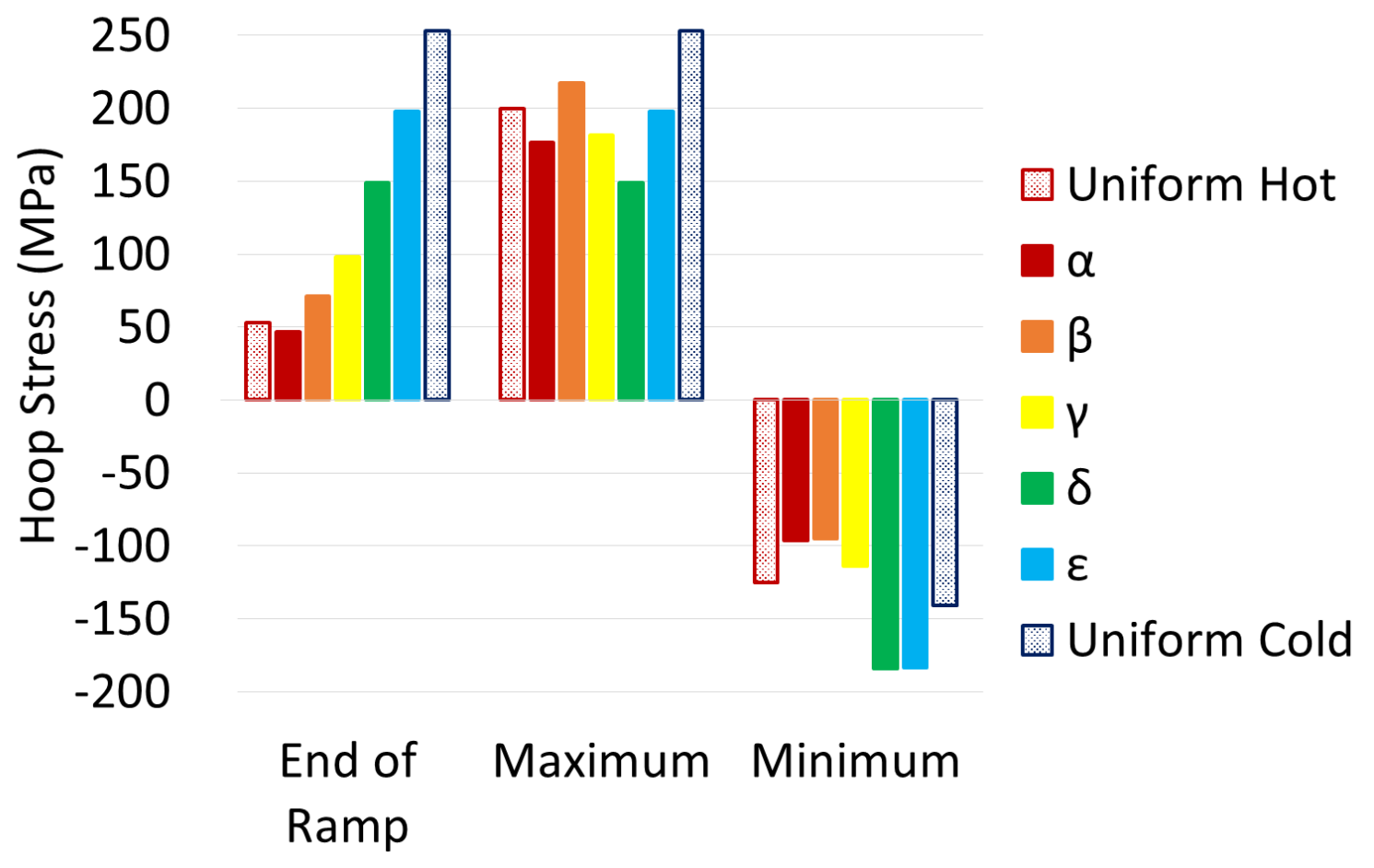

Figure 7 - The maximum and minimum hoop stress during the whole simulation, together with that at the end of the power ramp to $150 \%$ power at each of the key points in Figure 3, together with the equivalent positions in the uniform hot and cold models.

Together, Figure 6 and Figure 7 show that, with the exception of two points in compression (see Figure 7), the hoop stress of the hot and cold simulations effectively bounds that of the simulation with a cross-pin temperature tilt. The hoop stress at the end of the ramp to $150 \%$ power is a little reduced at point $\alpha$ compared to the hot model and at point $\varepsilon$ compared to the cold model, the reduction being 6 and $55 \mathrm{MPa}$ respectively. Similarly, the maximum hoop stress is reduced at points $\alpha$ and $\varepsilon$ compared to their equivalent uniform simulations (by 23 and $55 \mathrm{MPa}$ ). The minimum hoop stress reached at points $\delta$ and $\varepsilon$ is more compressive than that in the uniform simulation. This is however right at the beginning of the simulation and in reality is prior to any carbon deposition.

The simulations presented here suggest that modelling a pin with a cross-pin temperature tilt reduces the maximum hoop stress recorded during power ramps and full power operation compared to simulations that only model either uniform hot or cold cladding. 


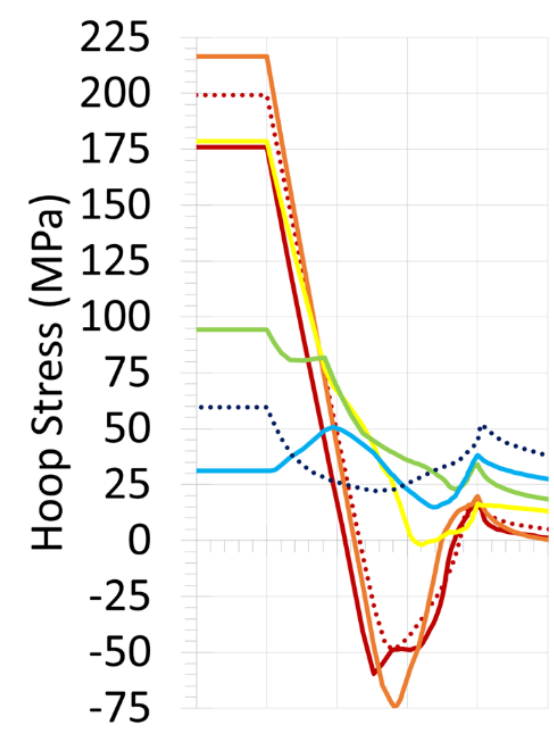

424344454647

(a)

\section{Outage Time (Days) (b)}

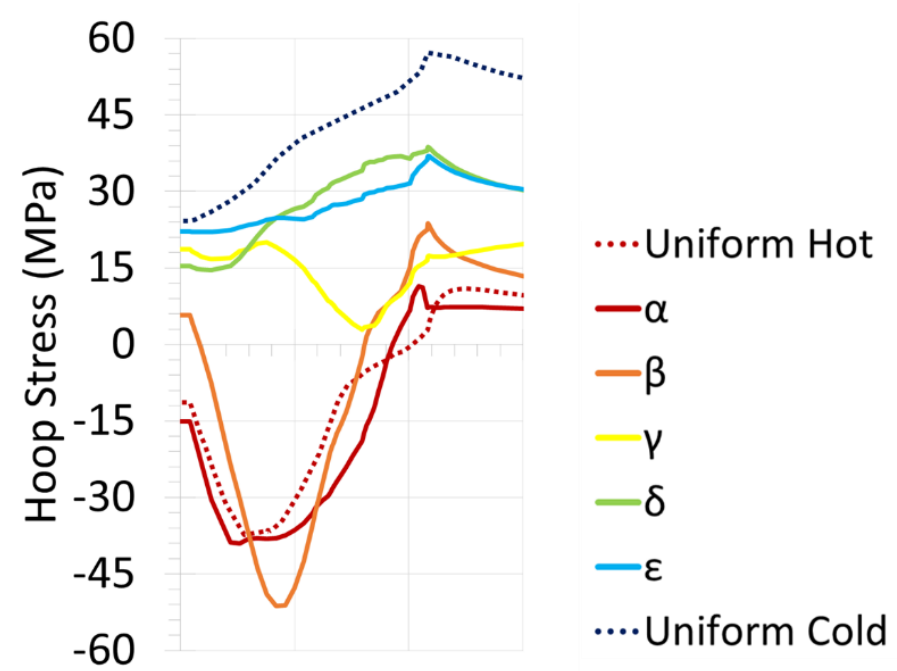

$30.4 \quad 30.6 \quad 30.8 \quad 31.0$

Reduced Power Time

(Days)

Figure 8 - The hoop stress during (a), the up-rate from the outage and (b), the up-rate from the period of reduced power operation at each of the key points in Figure 3, together with the equivalent positions in models with uniform temperature boundary conditions.

Figure 8 shows the hoop stress during the increases to full-power following the outage and period of reduced power operation. These are the two points during the simulation at which the uniformly deposited and un-deposited models do not bound the model with cross-pin temperature tilt. These points are however periods when the cladding is in compression and so will not cause cladding crack growth. The maximum magnitude hoop stress reached during the uprates is higher at point $\alpha$ and $\beta$ than in the uniform models. This is due to the greater crack tip opening shown in Figure 5. During the uprate from the outage (shown in Figure 8(a)), the minimum hoop stress at point $\alpha$ was $-59 \mathrm{MPa}$ and at point $\beta-74 \mathrm{MPa}$; this compares to -49 MPa in the uniformly hot model. Similarly, during the uprate from the period of low power operation (shown in Figure 8(b)), the minimum hoop stress at point $\alpha$ was $-51 \mathrm{MPa}$ and at point $\beta$-39 MPa; the minimum stress in the uniformly hot model was $-37 \mathrm{MPa}$. Whilst the stress during the period of low power operation was greatest in the uniformly hot model, the stress at point $\beta$ was greatest during the outage. The implications of this additional stress concentration are shown in Figure 9 and Figure 10. 


\section{Creep and Plastic Strains in the Cladding}

Figure 9 shows the creep and plastic strain predicted at each point in Figure 3 at the end of the simulation. Un-surprisingly, more creep strain is accrued in the hotter cladding, but more importantly, modelling cross-pin temperature tilt actually decreases the total creep strain accrued both on the cold and hot sides of the fuel during the entire simulation.

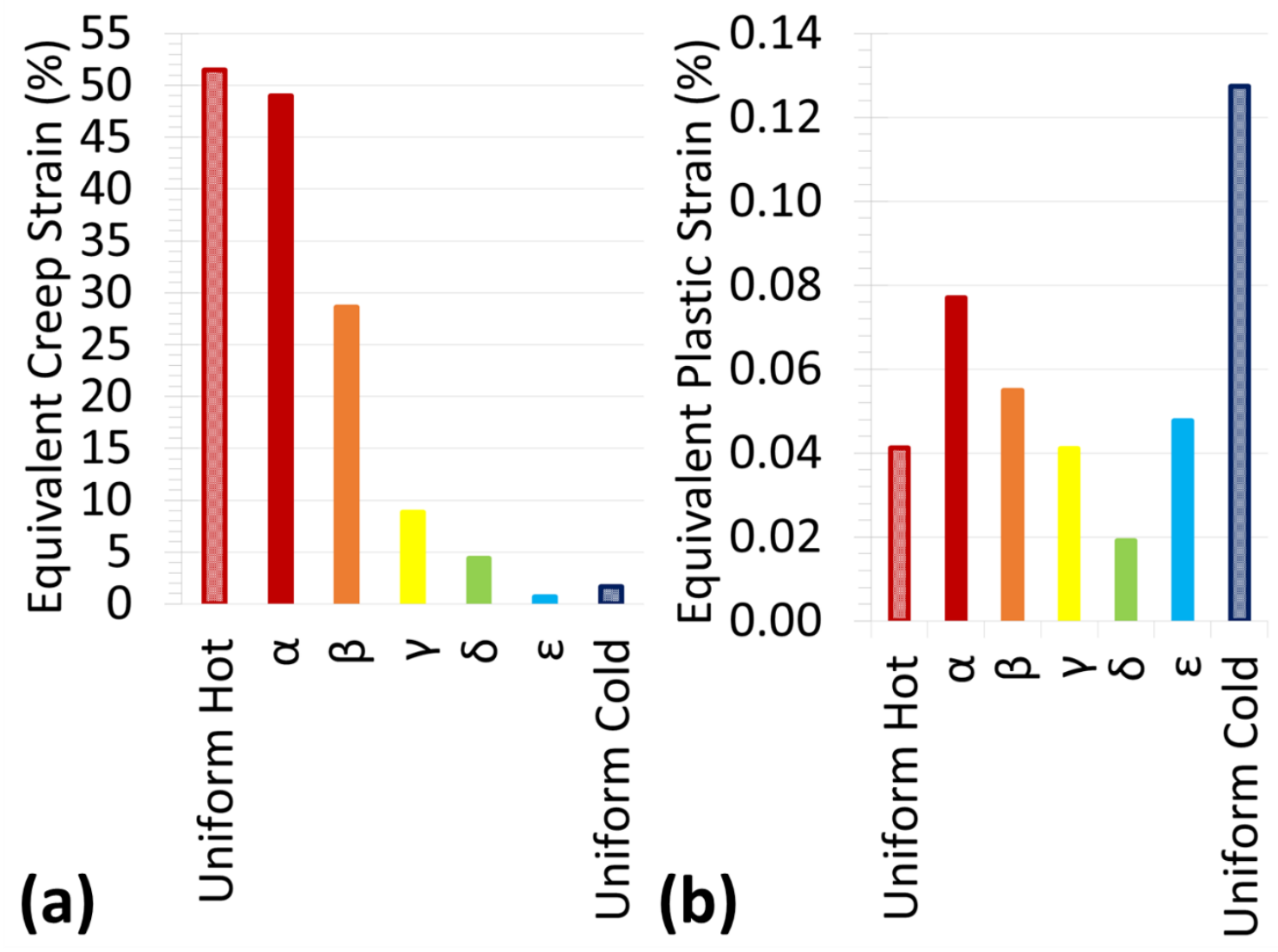

Figure 9 - The (a) creep and (b) plastic strain at the end of the simulation at each of the key points in Figure 3, together with the equivalent positions in models with uniform temperature boundary conditions.

Figure 9 (a) shows that the creep strain at the end of the ramp is much greater on the hot side of the cladding than the cold side -49.0 compared to $0.7 \%$. This is a consequence of the greatly increased temperature on the hot side. Of interest, the creep strain is marginally reduced at positions $\alpha$ and $\varepsilon$ compared to the equivalent uniform models (by 2.5 and $1.6 \%$ ). Whilst a lower creep strain on the hot side compared to the uniform model can be explained by less fuel volume being at an elevated temperature, one would expect the creep strain on the cold side to be greater compared to the uniform un-deposited model. The reduced creep strain is therefore likely to be due to an increased ability for fragments to move during so-called 'soft' PCMI and therefore accommodate power changes. 
The response of the cladding plastic strains is shown in Figure 9(b), which were around two orders of magnitude lower than the creep strains and followed a less clear pattern than the creep strains shown in Figure 9(a). The plastic strain in the uniformly deposited hot model and in the model with cross-pin temperature tilt were accrued during the up-rate from the outage (as shown in Figure 10). The plastic strain in the model with a uniform cold boundary condition was accrued during the ramp to $150 \%$ power. Whilst the plastic strain accrued during the entire simulation was bounded by the cold model, this would not have been the case had the ramp to $150 \%$ power been omitted. In that case the plastic strain would have been almost double in the model with cross-pin temperature tilt compared to without.

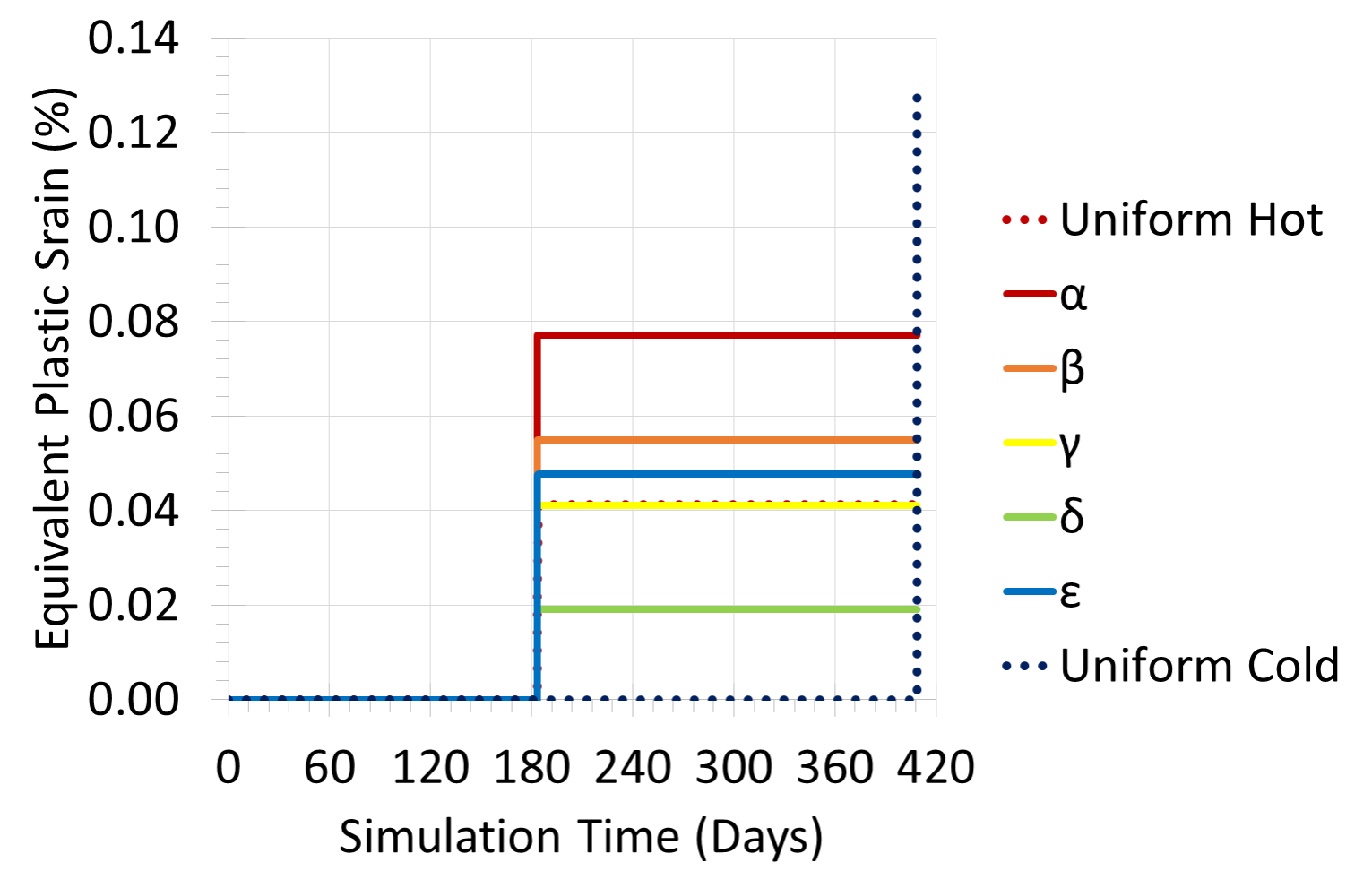

Figure 10 - The plastic strain during the entire simulation at each of the key points in Figure 3, together with the equivalent positions in the models with uniform temperature boundary conditions.

The increased stress observed in Figure 8 at points $\alpha$ and $\beta$ during the returns to power and during the outage did not result in any overall additional creep strain. This is likely to be due to the accrual of plastic strains (shown in Figure 10); the reduced operating temperatures; and, the behaviour once full power was reached. Whilst it appears that a slightly greater creep strain is accrued during the up-rates shown in Figure 11 the creep rates slow at positions $\alpha$ and $\beta$ once full power is reached meaning that the total creep strain accrued is lower. 


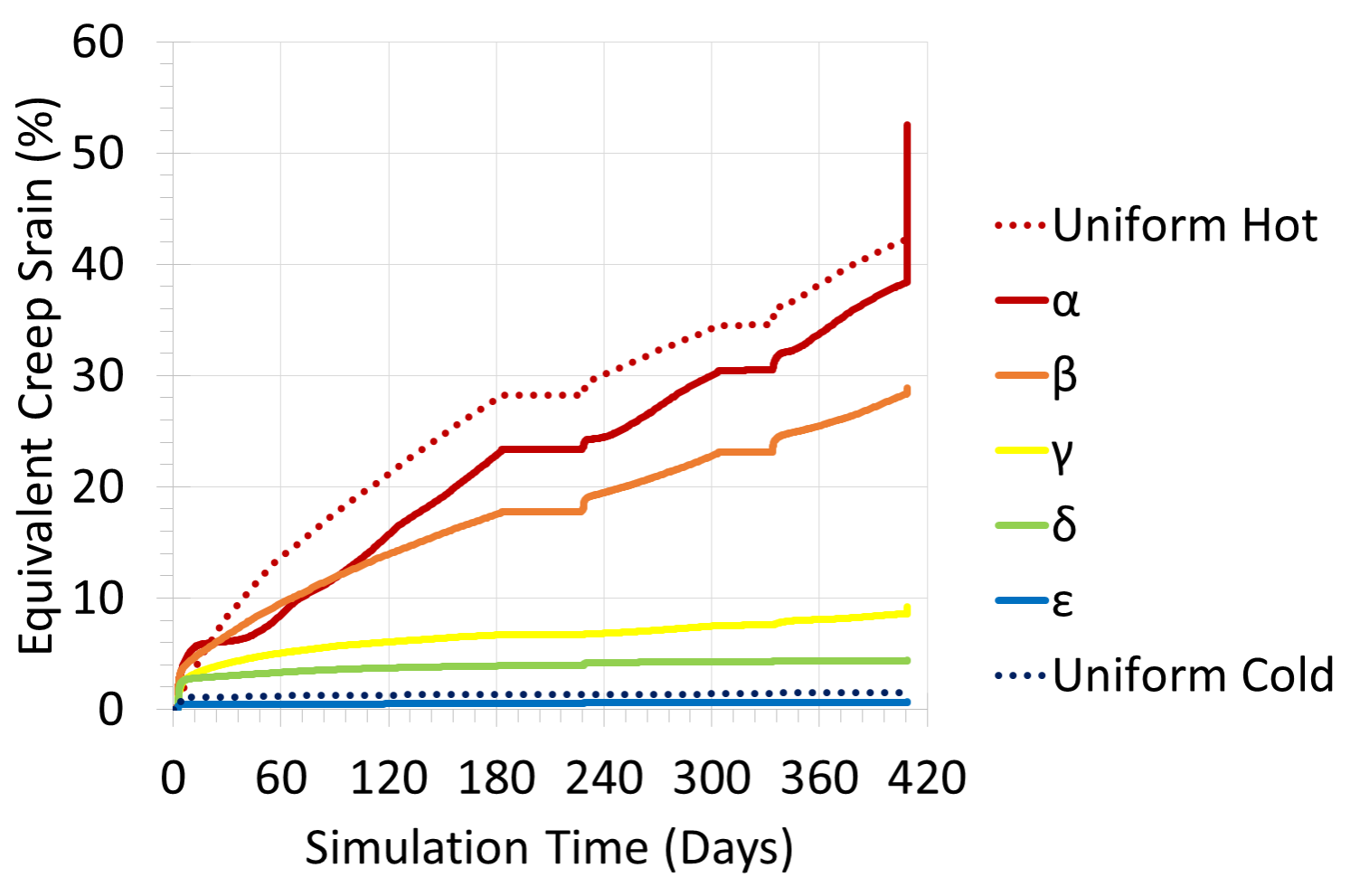

Figure 11 - The creep strain during the entire simulation at each of the key points in Figure 3, together with the equivalent positions in the models with uniform temperature boundary conditions.

\section{Effect of Cross-Temperature Tilt Magnitude}

Figure 12 compares the hoop stress and creep strain predicted at each point in Figure 3 at the end of the simulation for both a 100 and $200 \mathrm{~K}$ cross-pin temperature tilt. The same trends were seen for the 100 and $200 \mathrm{~K}$ cross-pin temperature tilt simulations:

- Increasing the temperature of the cladding increases the creep strain in the cladding. This is due to both increased fuel pellet swelling and an increased cladding creep rate.

- The increased creep rate leads to a reduction in the hoop stress.

- A secondary, smaller, effect is that the azimuthal motion of the fuel pellets in models with a cross-pin temperature tilt results in lower cladding stresses in models in which a cross-pin temperature tilt is modelled than when a uniformly hot or cold cladding temperature is assumed.

- This azimuthal motion of pellet motions produces a slight reduction in the creep strain in models in which cross-pin temperature tilt is explicitly modelled.

For the model with the smaller cross-pin temperature tilt, the reduction in the creep stress and hoop stress is still present, but is reduced in magnitude. For the creep strain in particular, the reduction in temperature from 200 to $100 \mathrm{~K}$ is very significant (of order $\mathrm{x} 10$ ) for the hot model 
and for hot regions of models with tilt. The hoop stress is also much more effected for hot regions but shows reductions of around $50 \%$.

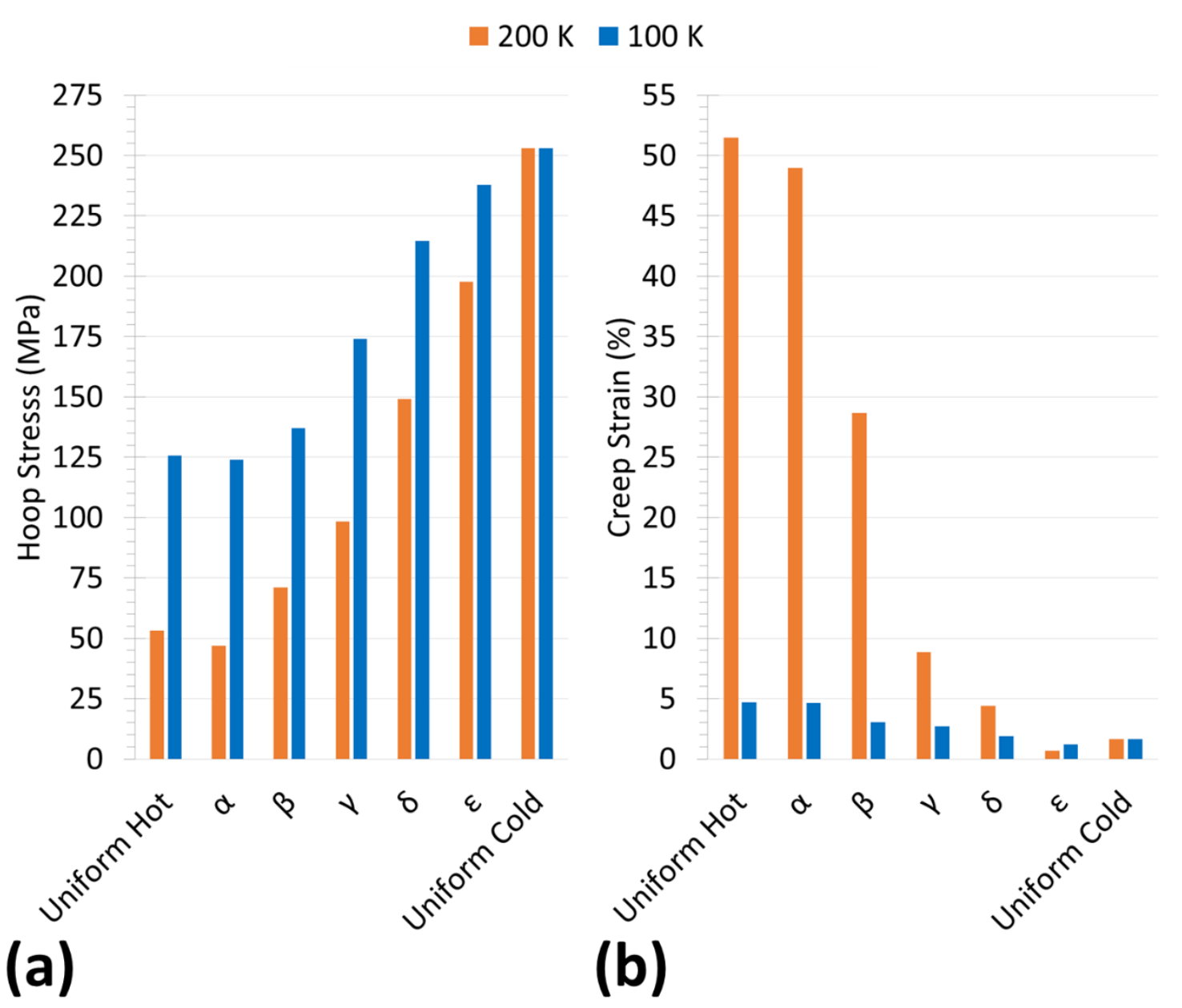

Figure 12 - (a) Hoop stresses and (b) creep strain at the end of the simulation at each of the key points in Figure 3, together with the equivalent positions in models with uniform temperature boundary conditions for simulations with a $100 \mathrm{~K}$ and $200 \mathrm{~K}$ cross-pin temperature tilt..

\section{Relevance to Other Reactor Systems}

Whilst the simulations in this paper represent the AGR system, the techniques may be readily applied to other reactor systems. Care must however be taken when extrapolating the results of this work to problems such as flux tilt in other reactor systems [36]. Firstly, flux tilting will affect the power deposition in the pellets and therefore their temperature and thermal expansion. Secondly, AGR fuel pellets contain a central bore. The opening and closure of pellet cracks at the bore and displacement of the bore itself form a significant part of the PCMI response of AGR fuel; this is demonstrated in Figure 5(b) and [25]. 


\section{Idealised Crack Patterns}

Upon brief examination of Figure 1, it is clear that the crack patterns modelled in this work are highly idealised. Fuel examined under PIE exhibits curved cracks and branching. More complicated crack patterns might affect heat transfer due to gaps opening between points of contact. In addition, the motion of the pellet fragments might be reduced due to increased difficulty of pellet sliding. One avenue currently being explored for the fracture of fuel pellets is peridynamics [37]-[39]. Peridynamics is designed to predict the complicated crack patterns frequently observed in PIE; crack patterns are not idealised and do not need to be imposed at the start of the simulation. Using peridynamics for work such as this would require the development of a coupled temperature-displacement peridynamic model for uranium dioxide; work is progressing in this direction [40]. Another way in which the model presented in this paper is idealised is in the position and nature of the thermal boundary condition. Whilst PIE reveals deposits that sometimes vary more abruptly [19], [20], these might be due to deposit spallation during handling post reactor operation.

\section{The Importance of a Cross-Pin Temperature Tilt}

This work has shown that elevated fuel and cladding temperatures due to the deposition of carbon increases the creep strain in the cladding. The impact of a cross-pin temperature tilt is to reduce the stress and creep strain slightly from that predicted in models with a uniformly hot or cold temperature. It is anticipated that variation in material properties and component manufacturing tolerances might have a greater effect. Nevertheless, we have shown that modelling a fuel pin with a cross-pin temperature tilt by fuel with uniform temperature cladding is likely to be conservative. 


\section{Conclusions}

Fuel Temperature Levels \& Pellet Fragment Motion

- Modelling a cross-pin temperature tilt rather than the hot and cold sides separately reduces the peak temperature in the fuel by $42 \mathrm{~K}$. Modelling a pin with a cross-pin temperature as a 'hot pin' therefore represents a thermally somewhat conservative, with implications for phenomena such as fission gas release, pellet swelling and ultimately PCMI.

- Due to azimuthal motion of the fuel pellets, the hot side was less constrained than it would be in a model in which the uniform hot clad boundary condition was applied. The opening and closing of the pellet cracks at the clad inner surface was greater in the model with a cross pin temperature than in a model with a uniform cladding temperature and motion at the pellet bore was less.

\section{Stress State in the Cladding}

- During full power operation and power ramps, modelling a pin with a cross-pin temperature tilt reduces the peak tensile hoop stress compared to simulations with uniformly deposited and un-deposited cladding. This is due to the greater ability of fuel pellet fragments to move to accommodate operational changes.

- The cladding hoop stress at the end of the ramp to $150 \%$ power was reduced by $6 \mathrm{MPa}$ on the hot side of the pin compared to the uniform hot model. On the cold side of the pin, the hoop stress was reduced by $55 \mathrm{MPa}$ compared to the uniform cold model.

- During the return to power from a power outage and reduced power operation, there was some additional stress concentration in the cladding due to increased pellet motion.

\section{Inelastic Strains in the Cladding}

- The increased temperature due to carbon deposition significantly increased the creep strain at the end of the ramp compared to an un-deposited pin. On the hot side of the pin, the creep strain was $49.0 \%$ compared to $1.6 \%$ in an un-deposited model.

- The creep strain was lower than in the equivalent uniform hot models (by $2.5 \%$ ). This shows that whilst carbon deposition increases the creep rate in the cladding and is more likely to cause failure, the imposition of azimuthally varying deposit does not in itself increase the creep damage in the cladding.

- The additional stress concentration in the cladding due to increased pellet motion during a power uprate from an outage resulted in greater plastic strains in the model with cross- 
pin temperature. However, during the ramp to $150 \%$ power, the plastic strain in the cold model was still greater than at any point in the model with an azimuthally varying temperature boundary condition.

- The plastic strain by the end of the simulation on the hot side was $0.077 \%$ and on the cold side was $0.048 \%$, this was greater than that predicted by the uniform hot model, but less than that predicted by the uniform cold model. 


\section{Acknowledgements}

Thomas Haynes would like to thank correspondence from Dr John Shea (formerly of EDF Energy); Dr Jonathon Ball (of EDF Energy) and Dr Ian Palmer (formerly of the UK National Nuclear Lab); technical support from EDF Energy's Fuel Group at Barnwood; insights from Dr Susan Morgan of the UK National Nuclear Lab, as well as the financial support of both EDF Energy and the EPSRC. Mark Wenman acknowledges financial support for the work by EPSRC and EDF Energy.

\section{Data Availability}

Some of the material properties data in this paper are derived from data provided by EDF Energy and currently not available for release.

\section{References}

[1] R. E. Pendlebury, "A 2000 hour test to investigate CAGR fuel pellet/clad bonding," Nucl. Electr., vol. TD/SID/MEM, 1992.

[2] J. H. Shea, G. A. Gates, S. L. Brown, and P. A. Tempest, "Modelling the effects of flexible operation on AGR fuel integrity," TopFuel '97 Trans., vol. 5, pp. 176-183, 1997.

[3] B. Cox, "Pellet-clad interaction (PCI) failures of zirconium alloy fuel cladding - a review," J. Nucl. Mater., vol. 172, pp. 249-292, 1990.

[4] M. L. Rossi and C. D. Taylor, "First-principles insights into the nature of zirconiumiodine interactions and the initiation of iodine-induced stress-corrosion cracking," $J$. Nucl. Mater., vol. 458, pp. 1-10, 2015.

[5] I. Schuster and C. Lemaignan, "Influence of texture on iodine-induced stress corrosion cracking of Zircaloy-4 cladding tubes,” J. Nucl. Mater., vol. 189, pp. 157-166, 1992.

[6] T. A. Haynes, J. A. Ball, J. H. Shea, and M. R. Wenman, "Modelling pellet-clad mechanical interaction during extended reduced power operation in bonded nuclear fuel," J. Nucl. Mater., vol. 465, pp. 280-292, 2015.

[7] D. J. Powell, R. Pilkington, and D. A. Miller, "The precipitation characteristics of $20 \%$ Cr/25\% Ni-Nb stabilised stainless steel," Acta Metall., vol. 36, no. 3, pp. 713-724, 1988.

[8] K. Klemetti, H. Hanninen, and J. Kivilahti, "The Effect of Sigma Phase Formation on the Corrosion and Mechanical Properties of Nb-Stabilized Stainless Steel Cladding," Weld. J. Res. Suppl., pp. 17-25, 1984. 
[9] C.-C. Hsieh and W. Wu, "Overview of Intermetallic Sigma (sigma) Phase Precipitation in Stainless Steels," ISRN Metall., vol. 2012, no. 4, pp. 1-16, 2012.

[10] S. Morgan, A. M. Gate, J. F. W. Thompson, and M. Barker, "Understanding Advanced Gas-Cooled Reactor (CAGR) Fuel Using Metallography," in TopFuel Reactor Fuel Performance 2012 Transactions, 2012, pp. 515-519.

[11] B. T. Kelly, "The radiolytic corrosion of advanced gas-cooled reactor graphite," Prog. Nucl. Energy, vol. 16, no. 1, pp. 73-96, 1985.

[12] M. Taylor, H. Evans, P. Smith, R. Ding, Y. L. Chiu, S. Rai, B. Connolly, N. Smith, L. Pearson, and C. Mowforth, "The Effect of Temperature and Carbonyl Sulphide on Carbon Deposition on 20Cr25Ni Stainless Steel," Oxid. Met., vol. 87, no. 5-6, pp. 667678, 2017.

[13] R. L. Faircloth, K. S. Norwood, and H. A. Prior, "Coolant chemistry of the advanced carbon dioxide cooled reactor," Spec. Meet. Cool. Chem. plate-out Decontam. gascooled React. Juelich, Fed. Repub. Ger. 2-4 December 1980, vol. IWGGCR-2, pp. 125$131,1980$.

[14] H. A. Prior and A. Harper, "Equipment for Irradiation Experiments in the Coolant Chemistry of the AGR," Proc. an Int. Top. Meet. Grenoble, Fr. Sept. 28-30, 1982, pp. $509-518,1983$.

[15] C. J. Wood, "Application of radiation chemistry research to the operation of nuclear reactors," Ann. Nucl. Energy, vol. 9, no. 4, pp. 195-208, 1982.

[16] D. Senior, "Chemistry of operating civil nuclear reactors," Off. Nucl. Regul., vol. Nuclear Sa, pp. 1-40, 2017.

[17] D. E. Shropshire, "Lessons Learned From GEN I Carbon Dioxide Cooled Reactors," in 12th International Conference on Nuclear Engineering, 2004, pp. 463-473.

[18] A. Keshmiri, "Three-dimensional simulation of a simplified advanced gas-cooled reactor fuel element," Nucl. Eng. Des., vol. 241, pp. 4122-4135, 2011.

[19] C. Gras and S. J. Stanley, "Post-irradiation examination of a fuel pin using a microscopic X-ray system: Measurement of carbon deposition and pin metrology," Ann. Nucl. Energy, vol. 35, pp. 829-837, 2008.

[20] C. W. Mowforth, K. Hinds, and N. Smith, "Control of Carbon Deposition within the 
Primary circuit of Advanced Gas-Cooled Reactors," in Chemistry in Energy, 2015, no. July.

[21] C. Mowforth, K. Hinds, and N. Smith, "Control of Carbon Deposition within the Primary Circuit of Advanced Gas-Cooled Reactors," EDF Energy, vol. 1st Chemis, 2015 .

[22] M. L. Sykes, I. A. S. Edwards, and K. M. Thomas, "Metal carbonyl decomposition and carbon deposition in the advanced gas-cooled nuclear reactor," Carbon N. Y., vol. 31, no. 3, pp. 467-472, 1993.

[23] S. Morgan, "Reactor Operations Support (National Nuclear Laboratory)," Pers. Commun., 2015.

[24] T. A. Haynes, J. A. Ball, J. H. Shea, and M. R. Wenman, "Finite element modelling of pellet-clad interaction during operational transients," TopFuel 2015 Oral Trans., pp. 62$71,2015$.

[25] T. A. Haynes, J. A. Ball, and M. R. Wenman, "Modelling the Role of Pellet Relocation in the (r- $\theta)$ Plane Upon Pellet-Clad Interaction in Advanced Gas Reactor Fuel," Nucl. Eng. Des., vol. 314, pp. 271-284, 2017.

[26] R. Mella and M. R. Wenman, "Axisymmetric whole pin life modelling of advanced gascooled reactor nuclear fuel," J. Nucl. Mater., vol. 437, no. 1-3, pp. 154-165, 2013.

[27] M. A. Reza, "Extending the Capabilities of the PELICAN Fuel Performance Code towards Axisymmetric and Clad Ballooning Modelling," MSc Nucl. Eng. Diss., 2017.

[28] T. A. Haynes, "Finite Element Modelling of Nuclear Fuel Performance in Advanced Gas-Cooled Reactors," PhD Thesis, Imp. Coll. London, vol. Awaiting E, 2018.

[29] I. D. Palmer, K. W. Hesketh, and P. A. Jackson, "A Model for Predicting the Radial Power Profile in a Fuel Pin," Water React. Fuel Elem. Perform. Comput. Model., pp. $321-335,1983$.

[30] K. Lassmann and F. Hohlefeld, "The revised URGAP model to describe the gap conductance between fuel and cladding," Nucl. Eng. Des., vol. 103, pp. 215-221, 1987.

[31] K. Lassmann, "URGAP, A Gap Conductance Model for Transient Conditions," Water React. Fuel Elem. Perform. Comput. Model., pp. 97-114, 1983.

[32] J. F. W. Thompson, "PIE Technician (National Nuclear Laboratory)," Pers. Commun., 
2015.

[33] B. Baurens, J. Sercombe, C. Riglet-Martial, L. Desgranges, L. Trotignon, and P. Maugis, "3D thermo-chemical-mechanical simulation of power ramps with ALCYONE fuel code,” J. Nucl. Mater., vol. 452, no. 1-3, pp. 578-594, 2014.

[34] G. F. Hewitt and J. G. Collier, "Introduction to Nuclear Power : 2nd Edition," Taylor Fr. New York, 2000.

[35] J. A. Ball, "Fuel Performance Engineer (EDF Energy),” Pers. Commun., 2013.

[36] E. N. Onder, L. K. H. Leung, and Y. F. Rao, "Effect of Element Flux Tilt on CHF," 13th Int. Top. Meet. Nucl. React. Therm. Hydraul. Kanazawa City, Ishikawa Prefect. Japan, Sept. 27-October 2, 2009, vol. N13P1227, no. September, pp. 1-13, 2009.

[37] R. Mella and M. R. Wenman, "Modelling fracture of nuclear fuel pellets during a power transient using peridynamics," J. Nucl. Mater., vol. 467, pp. 58-67, 2015.

[38] S. Oterkus and E. Madenci, "Peridynamic Modeling of Fuel Pellet Cracking," Eng. Fract. Mech., vol. 176, pp. 23-37, 2017.

[39] Y. Wang, X. Zhou, and M. Kou, "Peridynamic investigation on thermal fracturing behavior of ceramic nuclear fuel pellets under power cycles," Ceram. Int., vol. 44, pp. 11512-11542, 2018.

[40] L. Jones, G. Rossiter, and M. R. Wenman, "Modelling fracture of heterogenous ceramics using peridynamics," Second Work. Res. into Nucl. Fuel Cladding Eur. Lecco, Italy, 2017. 